\title{
LARYNGOCELE - REPORT OF A CASE
}

\author{
Pradhan $\mathrm{B}^{1}$, Amatya $\mathrm{R} \mathbf{C} \mathbf{M}^{1}$ \\ Bhusal $C L^{1}$, Singh $D^{1}$, Sharma $B^{1}$
}

\section{INTRODUCTION}

Laryngocele is an air filled dilation of the saccule of the laryngeal ventricle. Usually the saccule of the laryngeal ventricle regresses in size as the individual matures, saccule is said to be more common in men than in women. Laryngocele presumably results from an abnormally large saccule that extends up above the thyroid cartilage. This anomaly communicates freely with the laryngeal lumen and is filled with air. ${ }^{1,2}$

This case is reported due to its rarity. Incidence of laryngocele has not been studied in Nepal but incidence in $\mathrm{UK}$ is 1 per 2.5 million population per year and sex incidence is 5:1 in favour of men. Peak age incidence is $6^{\text {h }}$ decade and four out of five are unilateral. ${ }^{3}$

\section{CASE REPORT}

A 39 years old male, farmer by occupation presented with a history of progressive swelling in the left side of neck for last 3 years and hoarseness and discomfort in the throat for the same duration. The swelling was painless to begin with, it used to decrease in size with some kind of hissing noise of escaping of air when it was compressed and used to increase in size with the performance of valsalva maneuver. He gave history of rapid increase in size for last six months, and it has become painful.

On clinical examination of neck, there was a diffuse oval shaped swelling of $8 x 4 \mathrm{~cm}$ in left upper neck, extending from body and angle of mandible to the upper border of thyroid cartilage inferiorly, and 1 $\mathrm{cm}$ lateral to the midline of neck medially, and to the anterior border of the left sternocleido-mastoid muscle (SCM) laterally. Cough impulse was positive, swelling increase in size with valsatva maneuver. The surface of the swelling was smooth, margins were well defined, initially it was soft in consistency but later became cystic, it was compressible at the beginning but transillumination was negative and there was no visible pulsation.

1. T. U. Teaching Hospital, Maharajgunj, Kathmandu, Nepal.

Address for correspondence : Dr. Bibhu Pradhan, Asst. Prof.

Dept. of ENT

T. U. Teaching Hospital, Kaharajgunj

Post Box No.: 3578, Maharajgunj, Kathmandu, Nepal

Email: bibhuduga@yahoo.com

JNMA, October - December, 2002, 41 
On examination of oral cavity, it was found to be normal. On indirect laryngoscopy - a diffuse swelling in left lateral pharyngeal wall extending from the left valleculla to aryepiglottic fold and medial wall of left piriform sinus, left false vocal cord was swollen, left ventricle showed whitish mass in anterior one third. Right vocal cord was normal. Findings of indirect laryngoscopy were confirmed by flexible endoscopy and later by direct laryngoscopy.

Fig. 1

Fig. 1: X-ray soft tissue neck lateral view and $A P$ view showed an air containing space with air fluid level in left lateral, Pharyngeal wall at the level of body of hyoid bone.

Fig. 2

Fig. 2: CT Scan of neck was done which showed dilatation of left ventricle of larynx which is continuous with an air containing sac of external laryngocele.
FNAC from the swelling of neck revealed the ciliated columnar epithelium with some lymphoid cells and neutrophils. A provisional diagnosis of combined type of left sided laryngocele was made.

Patient was planned for excision by external lateral neck approach. Tracheostomy was done, horizontal incision was made at the level of hyoid bone from midline to anterior border of sternocleido-mastoid muscle.

Subplatysmal plane was raised, the cyst was visualized, which was dissected carefully towards its neck, the neck was found to be passing through the thyrohyoid membrane. For the complete removal of the neck of the laryngocele, the left upper half of the ala of thyroid cartilage which is the part lateral to the notch of thyroid cartilage was excised preserving the inner perichondrium. The neck of the cyst was identified and was ligated. Whole of the laryngocele with its neck was excised as shown in Fig. 3. The defect in thyrohyoid

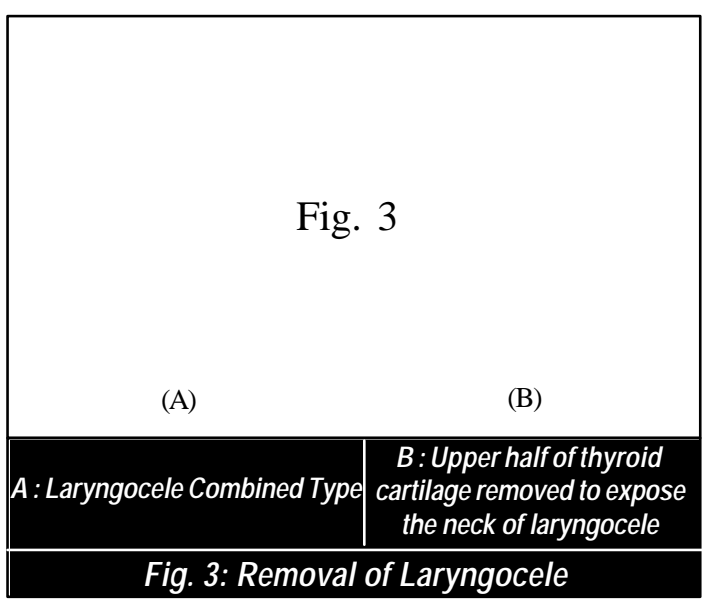

membrane was reconstructed using the preserved inner perichondrium of thyroid cartilage. Suction drain was kept, wound closed in two layers. Post operative period was uneventful, patient had no hoarseness. Patient was decanulated on $7^{\text {h }}$ post operative day. 
DISCUSSION

Three types of laryngocele have been described.

1. An internal laryngocele $(20 \%)$ is confined to the interior of the larynx, extending into the paraglottic region of the false vocal cord and aryepiglottic fold.

2. An external laryngocele $(30 \%)$ extends superiorly to the thyrohyoid membrane which it may penetrate at the point at which the superior laryngeal nerve enters. It is called external because it frequently presents as a mass lateral to the thyrohyoid membrene.

3. A combined internal - external laryngocele (50\%), has both internal and external components existing simultaneously.

If the communication between a laryngocele and the laryngeal lumen becomes obstructed, fluid may accumulate within the sac. If mucus is found a more appropriate term for the anomaly is a laryngomucocele and if pus is found it is called laryngopyocele.

Carcinoma of the larynx has been associated with unilateral laryngocele. In autopsy series, the incidence varies from $2-18 \%$. $^{5,6}$
Various techniques are described in text-book regarding the surgical management of laryngocele but most accepted one is external lateral neck approach.

\section{REFERENCES}

1. S tell P M , M arann A G D. H ead and neck surgery, L ondon, T hird edition, 1994, $71-72$.

2. C ivantos $F J, H$ olinger, $L . L$ aryngocele and saccular cyst in infant and children, A rch otolaryngol $\mathrm{H}$ ead \& $N$ eck surgery, 1992,118:296-300.

3. T hawley, $S E, B$ one, $R$ C, $L$ aryngocele, $L$ aryngoscope $1973,83: 362$.

4. C haries $W$. C ommings, J ohn $M$. F rednckson, $L$ ee A . $\mathrm{H}$ arker, $\mathrm{C}$ harles J, $\mathrm{K}$ rause, $\mathrm{D}$ avid $\mathrm{E}$. $\mathrm{S}$ chuller, $U S A$, otolaryngology $H$ ead and $N$ eck $S$ urgery, $3^{\circ}$ E dition, $\mathrm{V}$ ol. 3,2119- 2120.

5. M ichean, $C, L$ uboinski, $B . L$ anchi, $P, C$ achin, $Y$, $R$ elationship between I aryngocde and I aryngeal carcinoma. L aryngoscope, 1978,88:680.

6. $P$ apavella, S humrick, $O$ tolaryngology $H$ ead and $\mathrm{N}$ eck S urgery, 3d E dition, V ol. I || ,2308- 2310. 